Original Article

\title{
ANALYTICAL METHOD DEVELOPMENT FOR SIMULTANEOUS DETERMINATION OF UBIDECARENONE AND VITAMIN E ACETATE IN CAPSULE DOSAGE FORM BY HPLC
}

\author{
A. CAROLINE GRACE ${ }^{*}$, T. PRABHA ${ }^{1}$, M. JAGADEESWARAN ${ }^{1}$, K. SRINIVASAN ${ }^{2}$, T. SIVAKUMAR ${ }^{2}$
}

1Department of Pharmaceutical Analysis, Nandha College of Pharmacy, Erode 638052, Tamilnadu, India, ${ }^{2}$ Department of Pharmaceutical Chemistry, Nandha College of Pharmacy, Erode 638052, Tamilnadu, India

Email: carodani24@gmail.com

Received: 29 Sep 2018 Revised and Accepted: 23 Nov 2018

\section{ABSTRACT}

Objective: To develop and validate a new simple, accurate, precise and sensitive high performance liquid chromatographic method (HPLC) method for simultaneous estimation of ubidecarenone and vitamin $\mathrm{E}$ acetate in capsule dosage form as per international conference on harmonization (ICH) guidelines.

Methods: The chromatographic separation of drugs were achieved using hypersil $\mathrm{C}_{8}$ column $(250 \mathrm{~mm} \times 4.6 \mathrm{~mm}, 5 \mu)$ in isocratic elution mode with a mobile phase of methanol: ethanol: n-hexane $(80: 10: 10 \mathrm{v} / \mathrm{v} / \mathrm{v})$ at a flow rate of $1 \mathrm{ml} / \mathrm{min}$ with ultra-violet (UV) detection at $210 \mathrm{~nm}$.

Results: The optimized method produced sharp peaks with good resolution, minimum tailing factor and satisfactory retention time were found to be $5.745 \mathrm{~min}$ and $12.565 \mathrm{~min}$ for vitamin $\mathrm{E}$ acetate and ubidecarenone respectively. The method was linear in the range of $60-180 \mu \mathrm{g} / \mathrm{ml}$ for ubidecarenone and $20-60 \mu \mathrm{g} / \mathrm{ml}$ for vitamin E acetate with a correlation coefficient of 0.999 and 0.9993 respectively. Mean recoveries observed for ubidecarenone and vitamin E acetate were $99.85 \%$ and $99.73 \%$ respectively. The percentage relative standard deviation (\% RSD) of peak area for system precision, method precision, and intermediate precision were found to be less than $0.37 \%$. The lower degree of $\%$ RSD obtained has proved that the method was precise and robust.

Conclusion: A new simple HPLC method was developed and validated as per ICH guidelines for the simultaneous estimation of ubidecarenone and vitamin E acetate and the method can be effectively applied for the routine analysis of active pharmaceutical ingredient (API) and formulations.

Keywords: Ubidecarenone, Vitamin E acetate, HPLC, Method development, Coenzyme-Q10, alpha-tocopheryl acetate

(c) 2019 The Authors. Published by Innovare Academic Sciences Pvt Ltd. This is an open-access article under the CC BY license (http://creativecommons.org/licenses/by/4.0/) DOI: http://dx.doi.org/10.22159/ijpps.2019v11i1.30054

\section{INTRODUCTION}

Ubidecarenone is chemically 2-[(all-E)-3,7,11,15,19,23,27,31,35,39Decamethyltetraconta-2,6,10,14,18,22,26,30,34,38-decaenyl]-5,6dimethoxy-3-methylbenzene-1,4-dione, which is also called as coenzyme Q10 [1]. It is a lipid-soluble compound found naturally in plants, animals and in microorganisms [2]. It is a biologically active compound, characterized by a quinone ring attached to a repeating series of side chain isoprene units (fig. 1). It is an excellent anti-oxidant in the reduced state [3]. It is used as a dietary supplement and cardiovascular agent in congestive heart failure and in angina pectoris $[4,5]$.

Alpha-tocopherol is the most active form of vitamin $\mathrm{E}$ in humans. It is a powerful biological antioxidant play a fundamental part in the functioning of the human body [6]. Vitamin E in supplements is usually sold as vitamin E acetate (alpha-tocopheryl acetate). The synthetic form is labeled as DL-alpha-tocopheryl acetate (fig. 2), chemically known as All-rac-2, 5, 7, 8-tetramethyl-2-(4, 8, 12-trimethyltridecyl)3,4-dihydro-2H-1-benzopyran-6-yl acetate [7, 8]. Vitamin $\mathrm{E}$ has a strong anti-oxidant character, influences the activity of the nervous system and high level of supplementary alpha-tocopherol reduces mortality caused by cardiovascular diseases. Vitamin E was reported to be effective in reducing atherosclerosis progression in subjects with previous coronary artery bypass graft surgery not treated with lipidlowering drugs [9].<smiles>COC1=C(OC)C(=O)C(C(C)(C)C=C(C)CC=O)=C(C)C1=O</smiles>

Fig. 1: Chemical structure of ubidecarenone

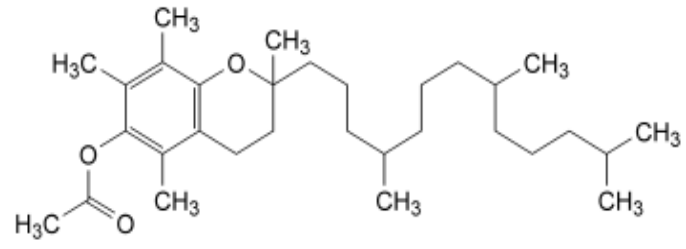

Fig. 2: Chemical structure of vitamin E acetate

The literature survey revealed that few UV spectrophotometric methods [1, 10, 11], HPLC [12-18] and bio-analytical [19, 20] methods were reported for the estimation of ubidecarenone alone or in combination with other drugs. And also several methods like HPLC [21-26], UV [27, 28] were described for vitamin E acetate alone or in combination with other drugs. But no method has been reported for the estimation of ubidecarenone and vitamin $\mathrm{E}$ acetate in the capsule dosage form. Hence the main objective of the proposed method was to develop and validate a simple, accurate and sensitive HPLC method for the simultaneous determination of ubidecarenone and vitamin $\mathrm{E}$ acetate in the capsule dosage form.

\section{MATERIALS AND METHODS}

\section{Chemicals and reagents}

Ubidecarenone and vitamin E acetate reference standards were obtained as gift sample from Sai Mirra Innopharm pvt ltd, Chennai and Surien pharmaceuticals, Chennai respectively. Zen Q10 capsule (Minova life sciences pvt ltd., Bangalore) was procured from the local market. Label claim of Zen Q10 capsule for ubidecarenone and vitamin E acetate is $100 \mathrm{mg}$ and $200 \mathrm{mg}$ respectively. Methanol, ethanol, and n-hexane (HPLC grade) were purchased from E. Merck India ltd., Mumbai. 


\section{Instrumentation and chromatographic conditions}

A shimadzu HPLC instrument-LC 20AD with UV-VIS SPD-20A detector was used. The data was recorded by using LC solution software.

The chromatographic separation of drugs was achieved using hypersil $\mathrm{C}_{8}$ column $(250 \mathrm{~mm} \times 4.6 \mathrm{~mm}, 5 \mu)$ in isocratic elution mode with a mobile phase of methanol: ethanol: n-hexane (80:10:10 $\mathrm{v} / \mathrm{v} / \mathrm{v}$ ) at a flow rate of $1 \mathrm{ml} / \mathrm{min}$ with UV detection at $210 \mathrm{~nm}$.

\section{Mobile phase preparation}

The mobile phase was prepared by mixing methanol, ethanol, and nhexane in the proportion of $80: 10: 10 \mathrm{v} / \mathrm{v} / \mathrm{v}$ and it was degassed by sonication for $15 \mathrm{~min}$.

\section{Preparation of standard solution}

$60 \mathrm{mg}$ of ubidecarenone and $20 \mathrm{mg}$ of vitamin $\mathrm{E}$ acetate was weighed accurately and transferred into a dry $100 \mathrm{ml}$ volumetric flask, $20 \mathrm{ml}$ of diethyl ether was added and sonicated for $5 \mathrm{~min}$. To the above solution, $30 \mathrm{ml}$ of ethanol was added and again sonicated for $20 \mathrm{~min}$. The volume was made up to $100 \mathrm{ml}$ with ethanol $(600 \mu \mathrm{g} / \mathrm{ml}$ of ubidecarenone and $200 \mu \mathrm{g} / \mathrm{ml}$ of vitamin E acetate). From the above stock solution, $10 \mathrm{ml}$ was pipetted out into a $50 \mathrm{ml}$ volumetric flask, and the volume was made with methanol. (120 $\mu \mathrm{g} / \mathrm{ml}$ of ubidecarenone and $40 \mu \mathrm{g} / \mathrm{ml}$ of vitamin $\mathrm{E}$ acetate).

\section{Preparation of sample solution}

The content of 10 capsules was mixed well, and the average content weight of one capsule was calculated. The average content weight of one capsule was weighed accurately and transferred to a dry $100 \mathrm{ml}$ volumetric flask. To this $20 \mathrm{ml}$ of diethyl ether was added and sonicated for $10 \mathrm{~min}$ and $30 \mathrm{ml}$ of ethanol was added and again sonicated for $15 \mathrm{~min}$. The above solution was filtered, and the volume was made up to $100 \mathrm{ml}$ with ethanol. This solution contains $1000 \mu \mathrm{g} / \mathrm{ml}$ of ubidecarenone and $2000 \mu \mathrm{g} / \mathrm{ml}$ of vitamin E acetate and it was appropriately diluted to get the concentration of 120 $\mu \mathrm{g} / \mathrm{ml}$ of ubidecarenone and $40 \mu \mathrm{g} / \mathrm{ml}$ of vitamin $\mathrm{E}$ acetate.

\section{Method development}

The initial chromatographic conditions were set based on the nature of drugs. The mobile phase composition was selected based on the solubility and polarity and the detection wavelength was selected based on the UV absorption property of the drugs. To optimize the method conditions trials were conducted by changing the chromatographic conditions initially selected to achieve satisfactory separation of drug peaks with proper peak shape, retention time, plate count, resolution and tailing factor.

\section{Method validation}

The developed method was validated according to ICH guidelines [29] for validation of analytical procedures. The method was validated for the parameters such as system suitability, specificity, precision, accuracy, linearity, robustness, and ruggedness, limit of detection (LOD) and limit of quantitation (LOQ).

\section{Specificity}

Specificity study was conducted to assess the interferences that may be caused by the presence of excipients and degradation products that may be expected to present in the sample. In the current work, specificity was demonstrated by injecting blank, placebo with excipients, standard solution and sample solution and the chromatograms were compared for interferences.

\section{Precision}

System precision of the method was verified from six replicates of standard solution, and percentage relative standard deviation (\% RSD) of peak area was calculated. Method precision was verified from six replicates of commercial formulation solution and \% RSD of percentage label claim was calculated.

\section{Accuracy}

The recovery studies were carried out by addition of standard drug solution at three concentration levels, $50 \%, 100 \%$ and $150 \%$ to the previously analyzed sample solution. The above solution was injected in triplicate for each level, and percentage recovery of the known added amount was calculated.

\section{Linearity}

Linearity was established from $50 \%-150 \%$ of working concentration at five concentration levels in the range between $60-180 \mu \mathrm{g} / \mathrm{ml}$ for ubidecarenone and $20-60 \mu \mathrm{g} / \mathrm{ml}$ for vitamin $\mathrm{E}$ acetate. The solution of each concentration was injected in triplicate, and the peak area for all the concentration levels was measured. Linearity is evaluated by plotting graph with peak area in $\mathrm{y}$-axis and concentration in the $\mathrm{x}$-axis.

\section{Robustness}

Robustness was assessed by slightly changing the optimized chromatographic such as parameters ratio of methanol in mobile phase composition $\pm 5 \%$ and flow rate $\pm 0.2 \mathrm{ml} / \mathrm{min}$.

\section{Ruggedness}

To verify the ruggedness of the method, the sample solution was analyzed in three replicates by different analysts using different instruments on different days. The \% RSD of \% mean assay was calculated.

\section{Limit of detection (LOD) and limit of quantitation (LOQ)}

LOD is defined as the lowest concentration of an analyte that an analytical method differentiates from background levels. The LOQ is defined as the lowest concentration that can be measured with acceptable accuracy, precision and variability. The LOD and LOQ were calculated from the linearity curve by using the formulae

$$
\begin{aligned}
& \text { LOD }=\frac{3.3 \sigma}{S} \\
& \text { LOQ }=\frac{10 \sigma}{S}
\end{aligned}
$$

Where $\sigma$ is the standard deviation of the $y$-intercept and $S$ is the slope of the calibration plot [29].

\section{RESULTS AND DISCUSSION}

\section{Method development}

As a part of method development, several trials were carried out with various columns of different dimensions and also with different compositions of the mobile phase. The separation of ubidecarenone and vitamin $\mathrm{E}$ acetate was achieved using hypersil $\mathrm{C}_{8}$ column $(250$ $\mathrm{mm} \times 4.6 \mathrm{~mm}, 5 \mu$ ) in isocratic elution mode with a mobile phase of methanol: ethanol: $n$-hexane $(80: 10: 10 \mathrm{v} / \mathrm{v} / \mathrm{v})$ at a flow rate of 1 $\mathrm{ml} / \mathrm{min}$ with UV detection at $210 \mathrm{~nm}$. The drug peaks were identified by comparing the individual drug chromatogram of ubidecarenone and vitamin E acetate standard (fig. 3, fig. 4).

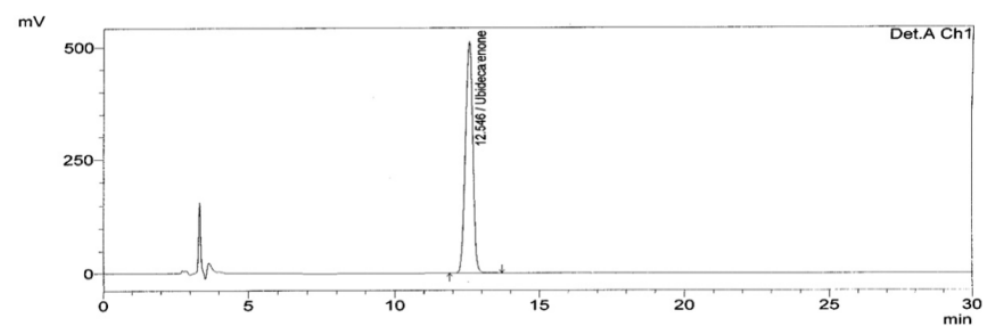

Fig. 3: Ubidecarenone standard 


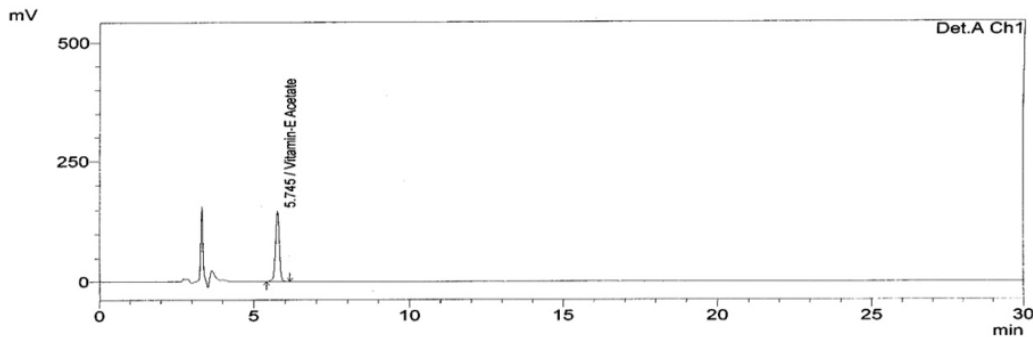

Fig. 4: Vitamin E acetate standard

To optimize the chromatographic conditions, the system suitability tests were applied to the chromatographic system to ensure the satisfactory performance of the method. Retention time, a number of theoretical plates and asymmetric peak factor was evaluated for six replicate injections of the standard at working concentration. The system suitability parameters were within the acceptance limit and are given in table 1 .

Table 1: System suitability parameters

\begin{tabular}{lll}
\hline Parameters & Vitamin E acetate & Ubidecarenone \\
\hline Resolution & & 7.6 \\
Tailing factor & 1.08 & 1.04 \\
Number of theoretical plates & 10022 & 11191 \\
Retention time (min) & 5.725 & 12.565 \\
\hline
\end{tabular}

Each value is average of six determinations $(n=6)$

The applicability of the method was tested by injecting the solution of the commercial formulation at working concentration. The peak area responses were recorded, and the percentage label claim was calculated. The percentage label claim for ubidecarenone and vitamin E acetate was found to be $101.60 \%$ and $99.46 \%$ respectively. The assay of the drug combination in the sample is ranging within the acceptance limit $98-102 \%$, which is the standard level in any pharmaceutical quality control.

\section{Method validation}

\section{Specificity}

$\mathrm{mV}$

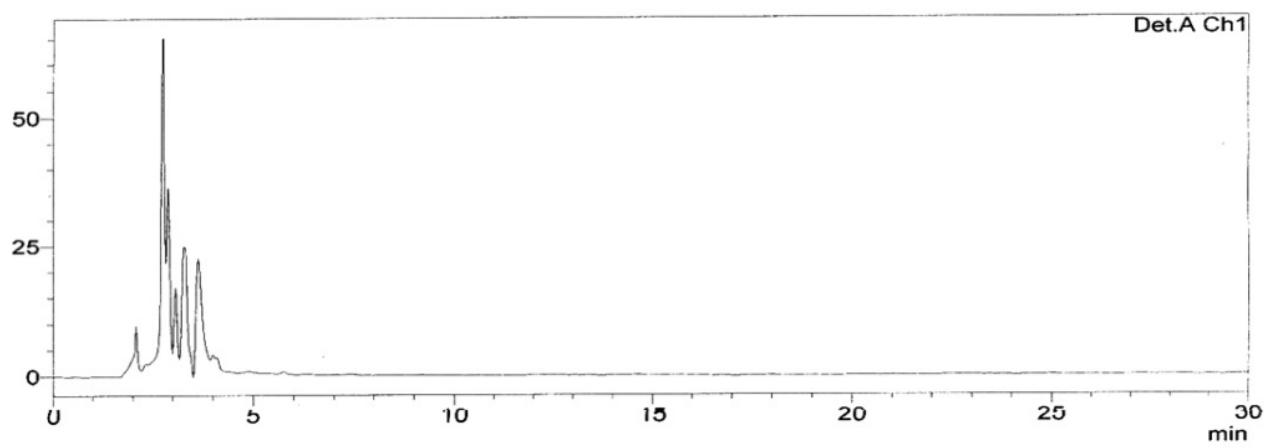

Fig. 5: Specificity-blank

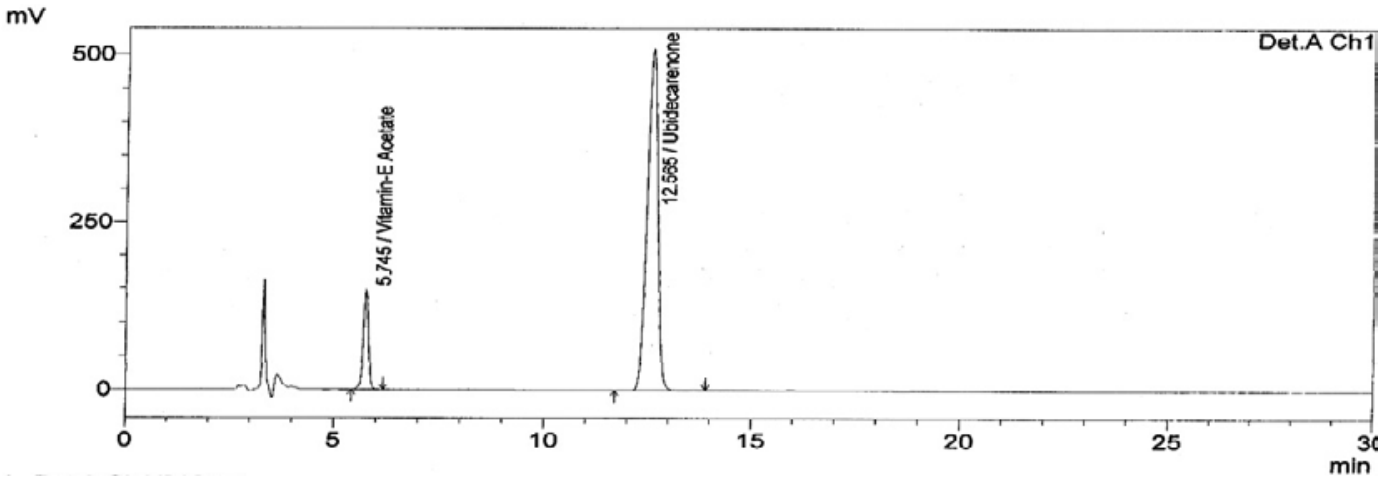

Fig. 6: Specificity-mixed standard 


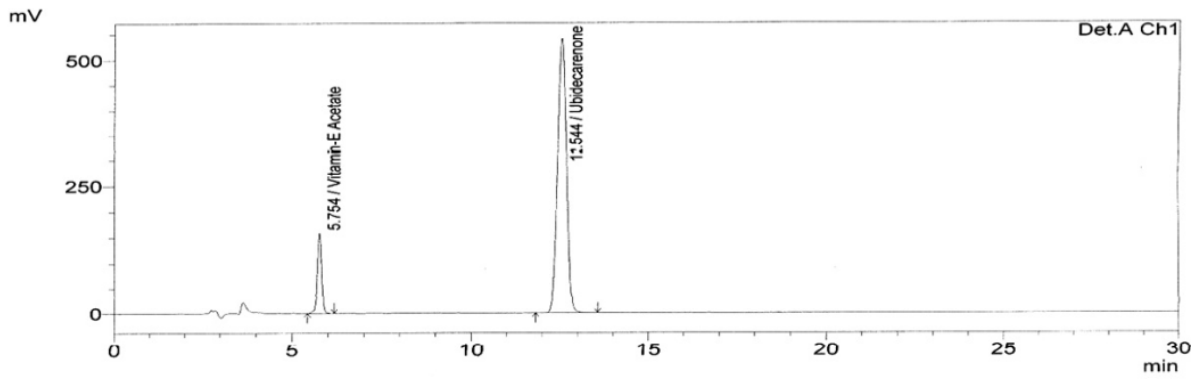

Fig. 7: Specificity-placebo mixed sample solution

Specificity of the method was tested by comparing the response of blank (fig. 5), standard (fig. 6) and placebo mixed sample solution (fig. 7). No interference of the placebo was detected at the retention time of ubidecarenone and vitamin E acetate. This confirms the specificity of the proposed method.

\section{Precision}

System precision of the method was evaluated by six replicate injections of standard solution and the \% RSD was found to be 0.36 for ubidecarenone and 0.19 for vitamin $E$ acetate.

Method precision was tested by six replicate injections of commercial formulation solution and the $\%$ RSD of percentage label claim was found to be 0.37 and 0.34 respectively. For both system and method precision, the \% RSD of response was less than 2 indicates the method is precise.

\section{Accuracy}

To check the accuracy of the method, recovery studies were carried out by adding standard drug at three concentration levels $50 \%$, $100 \%$, and $150 \%$. At each level, three determinations were performed, and the percentage mean recovery was calculated. All observed data are within the acceptance limit of percentage recovery $98-102 \%$, which indicates the accuracy of the developed method. The results obtained are shown in table 2 .

Table 2: Accuracy data (Analyte recovery study)

\begin{tabular}{lllll}
\hline \% Level & Amount added $(\boldsymbol{\mu g} / \mathbf{m l})$ & ${ }^{*}$ Amount recovered $(\boldsymbol{\mu g} / \mathbf{m l})$ & *\% Recovery & Mean \% recovery \\
\hline Ubidecarenone 50\% & 60 & $59.95 \pm 0.03$ & $99.92 \pm 0.05$ & 99.85 \\
Ubidecarenone 100\% & 120 & $119.71 \pm 0.11$ & $99.75 \pm 0.09$ & \\
Ubidecarenone 150\% & 180 & $179.80 \pm 0.08$ & $99.88 \pm 0.04$ & \\
Vitamin E acetate 50\% & 20 & $19.998 \pm 0.010$ & $99.99 \pm 0.053$ & 99.73 \\
Vitamin E acetate 100\% & 40 & $39.76 \pm 0.015$ & $99.43 \pm 0.030$ & \\
Vitamin E acetate 150\% & 60 & $59.875 \pm 0.011$ & $99.79 \pm 0.017$ & \\
\hline
\end{tabular}

${ }^{*}$ mean \pm SD of three replicates $(\mathrm{n}=3)$

\section{Linearity and range}

Linearity was established over the concentration level of $50 \%$ to $150 \%$ of the standard working concentration of ubidecarenone and vitamin $\mathrm{E}$ acetate. The five-point calibration curve obtained by plotting peak area versus concentration of ubidecarenone and vitamin $\mathrm{E}$ acetate was found to be linear within the concentration range from 60 to 180 $\mu \mathrm{g} / \mathrm{ml}$ and 20 to $60 \mu \mathrm{g} / \mathrm{ml}$ respectively. The linear regression was used for data evaluation. The linearity was expressed as a correlation coefficient; the value meets the acceptance criteria for both the drugs which are greater than 0.9993 . Hence the method is said to be linear. The linearity results are tabulated in table 3.

Table 3: Linearity data

\begin{tabular}{lll}
\hline Parameters & Ubidecarenone & Vitamin E acetate \\
\hline Slope & 78457 & 31058 \\
Intercept & 24183 & 14571 \\
Correlation coefficient $\left(\mathrm{R}^{2}\right)$ & 0.999 & 0.9993 \\
Range & $60-180 \mu \mathrm{g} / \mathrm{ml}$ & $20-60 \mu \mathrm{g} / \mathrm{ml}$ \\
\hline
\end{tabular}

\section{Robustness}

The robustness of the method was demonstrated by making slight changes in the chromatographic conditions such as a change in the mobile phase composition and flow rate in the assay of sample preparations.
The $\%$ RSD of $\%$ assay for the altered conditions was found to be less than $2 \%$. This represents the ability of the method to produce accurate results during the slightly distorted method conditions. The data is presented in table 4 .

Table 4: Results of robustness study

\begin{tabular}{llllll}
\hline Factor & \multirow{2}{*}{ Level } & \multicolumn{2}{l}{ mean \pm SD of \% Assay* } & \% RSD & \\
\cline { 3 - 6 } & & Ubidecarenone & Vitamin E acetate & Ubidecarenone & Vitamin E acetate \\
\hline Ratio of methanol in the mobile phase & 75 & $101.59 \pm 0.67$ & $99.58 \pm 0.08$ & 0.66 & 0.09 \\
& 80 & $101.45 \pm 0.57$ & $99.26 \pm 0.36$ & 0.56 & 0.36 \\
& 85 & $102.30 \pm 0.14$ & $100.15 \pm 1.02$ & 0.14 & 1.02 \\
Flow rate (ml/min) & 0.8 & $100.60 \pm 1.43$ & $100.18 \pm 0.30$ & 0.97 & 0.36 \\
& 1.0 & $101.45 \pm 0.57$ & $99.26 \pm 0.36$ & 0.56 & 0.30 \\
& 1.2 & $100.77 \pm 1.19$ & $99.40 \pm 0.55$ & 0.87 & 0.55 \\
\hline
\end{tabular}

*Mean of three replicates $(\mathrm{n}=3)$ 


\section{Ruggedness}

The mean assay percentage of ubidecarenone and vitamin $\mathrm{E}$ acetate in sample preparation was determined as per methodology by different analysts on different instruments on different days, and the results are given in table 5 . The observed value of within-laboratory variations showed no marked changes in the mean assay percentage of both the drugs, confirms the reproducibility of the proposed method.

Table 5: Ruggedness data

\begin{tabular}{|c|c|c|c|c|}
\hline \multirow[t]{2}{*}{ Parameter } & \multicolumn{2}{|c|}{ mean \pm SD of $\%$ assay* } & \multicolumn{2}{|l|}{$\%$ RSD } \\
\hline & Ubidecarenone & Vitamin E acetate & Ubidecarenone & Vitamin E acetate \\
\hline Day 1 & $101.45 \pm 0.57$ & $99.26 \pm 0.36$ & 0.56 & 0.36 \\
\hline Day 2 & $101.61 \pm 0.15$ & $100.24 \pm 0.39$ & 0.15 & 0.39 \\
\hline Analyst 1 & $101.45 \pm 0.57$ & $99.26 \pm 0.36$ & 0.57 & 0.36 \\
\hline Analyst 2 & $101.59 \pm 0.09$ & $100.06 \pm 0.77$ & 0.09 & 0.77 \\
\hline Instrument 1 & $101.45 \pm 0.57$ & $99.26 \pm 0.36$ & 0.57 & 0.36 \\
\hline Instrument 2 & $101.53 \pm 1.24$ & $99.49 \pm 0.60$ & 1.12 & 0.66 \\
\hline
\end{tabular}

*Mean of three replicates $(n=3)$

\section{LOD and LOQ}

The LOD of ubidecarenone and vitamin $\mathrm{E}$ acetate was found to be $5.06 \mu \mathrm{g} / \mathrm{ml}$ and $1.55 \mu \mathrm{g} / \mathrm{ml}$ respectively. The LOQ of ubidecarenone and vitamin E acetate was found to be $15.33 \mu \mathrm{g} / \mathrm{ml}$ and $4.71 \mu \mathrm{g} / \mathrm{ml}$ respectively.

\section{DISCUSSION}

Based on the literature review there is no HPLC method development was reported for the simultaneous estimation of ubidecarenone and vitamin $\mathrm{E}$ acetate in the capsule dosage form. The results of the system suitability and applicability of the method in the estimation of the drug combination in the marketed capsule dosage form confirm that the proposed method is suitable and applicable for routine laboratory analysis. The method validation results of the present study are within the specified acceptance criteria as per ICH guidelines [29]. The \%RSD of the precision study and robustness is less than $2 \%$ which indicates the repeatability, reproducibility, and strength of the method to withstand the variation in the method conditions, The mean \% recovery is within $98-102 \%$, the correlation coefficient calculated from the linearity study is greater than 0.99 and the very low LOD and LOQ values prove that the intended method is accurate, linear and extremely sensitive. Hence this method can be effectively applied for the separation and determination of the drugs ubidecarenone and vitamin $\mathrm{E}$ acetate.

\section{CONCLUSION}

A new simple HPLC method was developed for simultaneous estimation of ubidecarenone and vitamin $\mathrm{E}$ acetate in the capsule dosage form. The method provides good resolution between the drugs with less retention time. The results of validation parameters have proved that the proposed method is precise, accurate, robust and sensitive. The sample recoveries in the formulation were in good agreement with their respective label claim and they indicated the non-interference of formulation excipients in the estimation. Therefore the proposed study results confirm that the developed method is a suitable technique for simultaneous estimation of ubidecarenone and vitamin $\mathrm{E}$ acetate in the combined dosage form.

\section{AUTHORS CONTRIBUTIONS}

The research work and manuscript preparation were done by mrs. A. Caroline Grace; the research work was guided by Dr. T. Prabha, calculations and data interpretation was supported by Dr. M. Jagadeeswaran, critical revision of the manuscript was done by Dr. K. Srinivasan and final version of the manuscript were approved by Dr. T. Sivakumar.

\section{CONFLICTS OF INTERESTS}

Declared none

\section{REFERENCES}

1. The European Pharmacopeia. 5th ed. Strasbourg, France: EDQM, Council of Europe; 2005. p. 2157.
2. Astridani Rizky Putranti, Riesta Primaharinastiti, Esti Hendradi. Effectivity and physicochemical stability of nanostructured lipid carrier coenzyme Q10 in a different ratio of lipid cetyl palmitate and alpha tocopheryl acetate as a carrier. Asian J Pharm Clin Res 2017;10:146-52.

3. Manal Abdulkhaliq Ibrahim, Nada Naji Al-shawi. Effects of vitamin $\mathrm{E}$ and coenzyme Q10 supplementation against doxorubicin-induced neurotoxicity in rats. Asian J Pharm Clin Res 2018;11:402-6.

4. Boicelli CA, Ramponi C, Casali E, Masotti L. Ubiquinones: stereochemistry and biological implications. Membr Biochem 1981;4:105-18.

5. Bonakdar RA, Guarneri E. Coenzyme Q10. Am Fam Physician 2005;72:1065-70.

6. Mohammed Sarhan KKA, Mebin Aliasa, Sambath Kumar R. A review on novel uses of vitamin E. J Crit Rev 2017;5:10-4.

7. The European Pharmacopeia. $5^{\text {th }}$ ed. Supplement 5.1, Strasbourg, France: EDQM, Council of Europe; 2005. p. 3024.

8. Sanjay Kumar Gupta, Munagala Gayatri Ramya, Rajesh Akki, Singaram Kathirvel, Vadithe Vasu Naik. Development and validation of new RP-HPLC methods for stability study of fatsoluble vitamins. Int J Pharm Pharm Sci 2013;5:71-5.

9. Maria Laura Colombo. An Update on Vitamin E. Tocopherol and tocotrienol-perspectives. Molecules 2010;15:2103-13.

10. Mailvelan R, Mounnissamy VM, Selvamani P, Rajesh J, Raviraj T. Development and validation of UV spectrophotometric methods for the simultaneous estimation of ubidecarenone (coenzyme q-10) and clomifene citrate in bulk and tablet dosage forms. Asian J Res Chem Pharm Sci 2013;1:23-30.

11. Karpinska J, Mikołuc B, Piotrowska Jastrzebska. J application of derivative spectrophotometry for determination of coenzyme Q10 in pharmaceuticals and plasma. J Pharm Biomed Anal 1998;17:1345-50.

12. The Japanese pharmacopeia. Part I. $14^{\text {th }}$ ed. Ministry of health, Labour and welfare, Tokyo; 2002. p. 832.

13. Estevez PN, Tripodi V, Buontempo F, Lucangioli S. Coenzyme Q10 stability in pediatric liquid oral dosage formulations. Farm Hosp 2012;36:492-7.

14. Saravanamuthukumar M, Palanivelu M, Anandarajagopal K, Sridharan D. Simultaneous estimation and validation of atorvastatin calcium and ubidecarenone (coenzyme Q10) in combined tablet dosage form by the RP-HPLC method. Int J Pharm Pharm Sci 2010;2:36-8.

15. Kannappan N, Sasidharan DK, Ramkumar P, Prajapati MK, Panda PP. Analytical method development and validation of atorvastatin calcium and ubidecarenone tablet by RP-HPLC. Int J Pharm Sci Res 2011;2:1679-82.

16. Mailvelan R, Rajesh J, Selvamani P, Latha S. HPLC method development and validation for simultaneous estimation of ubidecarenone and clomifene citrate in bulk and tablet dosage forms. Int J Res Pharm Nano Sci 2012;1:61-9.

17. Claude Leray, Margaret D. Andriamampandry, monique freund, christian gachet, jean-pierre cazenave. Simultaneous determination of homologues of vitamin $E$ and coenzyme $Q$ 
and products of $\alpha$-tocopherol oxidation. J Lipid Res 1998; 39:2099-105.

18. Debra Orozco, Jules Skamarack, Kelly Reins, Barry Titlow, Steve Lunetta, Fang $\mathrm{Li}$, et al. Determination of ubidecarenone (Coenzyme Q10, Ubiquinol-10) in raw materials and dietary supplements by high-performance liquid chromatography with ultraviolet detection: single-laboratory validation. J AOAC Int 2007;90:1227-36

19. Claudia Cristina Ferreiro Barros, Eduardo Kinio Sugawara Livia Rentas Sanches. Determination of a method for extraction of coenzyme Q10 in human plasma: optimization of the use of surfactants and other variables. Einstein (São Paulo) 2012;10:203-8

20. Adrian A Franke, Cynthia M Morrison, Jesse L Bakke, Laurie J Custer, Xingnan Li, Robert V Cooney. Coenzyme Q10 in human blood: native levels and determinants of oxidation during processing and storage. Free Radical Biol Med 2010;48:1610-7.

21. Kareti Srinivasa Rao, Nargesh K Keshar, Nikhil V Belorkar, Bhanoji Rao ME, Srinivasa K, Ajay Kumar Pattnaik. A simple and rapid HPLC method for the simultaneous determination of vitamin-a and vitamin-e in tablet dosage forms. Res J Chem Environ Sci 2013;1:2-6.

22. Ubaldi A, Delbono G, Fusari A, Serventi P. Quick HPLC method to determine vitamin E concentration in cois milk. Ann Fac Medic Vet Di Parma 2005;25:101-10.

23. Anuradha SN, Arunkumar S. A validated RP-HPLC method for simultaneous estimation of vitamin a and vitamin $\mathrm{e}$ in multivitamin tablet dosage form. Int J Pharma Bio Sci 2012;3:322-7.

24. Prabakaran R, Chenthilnathan A, Vikraman S. Validation of simultaneous determination of vitamin an acetate and vitamin e acetate in multivitamin tablets by RP-HPLC. Int J Pharm Biol Chem Sci 2014;3:27-34.

25. Brabcova I, Kovarova L, Satinsky D, Havlikova L, Solich P. A fast HPLC method for determination of vitamin e acetate in dietary supplements using monolithic column. Food Anal Methods 2013;3:380-5.

26. Hong Min Lee, Byung Man Kwak, Jang Hyuk Ahn, Seung Hwan Jeong, Sung Lye Shim, Kyong Su Kim, et al. Simultaneous determination of vitamin a and e in infant formula by HPLC with photodiode array detection. Korean J Food Sci Ani Resour 2011;31:191-9.

27. Kumar Ashok, Rajput Gaurav Kumar. To develop a simple (UVVIS Spectrometric) method for the estimation of multivitamin with special reference to capsules and tablets. Int J Pharm 2011;2:43-8.

28. Rutkowski M, Grzegorczyk K. Modifications of spectrophotometric Methods for antioxidative vitamins determination convenient in analytic practice. Acta Sci Pol Technol Aliment 2007;6:17-28.

29. International conference on harmonization of technical requirements for registration of pharmaceuticals for human use. Validation of analytical procedures: Text and methodology ICH Q2 (R1); 2005. 